\title{
O Dilema Cooperação-Competição em Mercados Concorrenciais: o Conflito do Oligopólio Tratado em um Jogo de Empresas
}

\author{
Antonio Carlos Aidar Sauaia \\ David Kallás
}

\begin{abstract}
RESUMO
O objetivo deste estudo é discutir o dilema sempre atual enfrentado por firmas formadoras de preços: cooperar tacitamente pelos lucros (conluio) ou competir agressivamente pelo mercado (combate). Um experimento adotado como método de investigação produziu dados primários coletados num Jogo de Empresas (MMG). A análise descritiva, apoiada nos modelos de Atratividade de Indústrias, Análise Microeconômica, Teoria dos Jogos e Análise de Stakeholders, comparou os resultados na cooperação e na competição, mostrou que a competição prejudicou gestores (lucros negativos), governo (menos tributos) e investidores (preço das ações $23 \%$ menor). Em contrapartida produziu alguns benefícios não sustentáveis: consumidores compraram $22 \%$ mais produtos a preços $10 \%$ menores; duplicou o número de centros de distribuição e de vendedores e estes elevaram sua renda (46\%); produziu-se $21 \%$ mais computadores e $5 \%$ mais placas de memória; contratou-se $13 \%$ mais operários e investiu-se $63 \%$ mais recursos em tecnologia (P\&D). Conclui-se que para neutralizar os malefícios da competição e promover crescimento econômico sustentável deve-se buscar formas legais de cooperar na competição, assegurando atratividade ao setor, melhoria salarial com responsabilidade social, criação e manutenção de empregos, produtos de qualidade, preços baixos e direitos do consumidor.
\end{abstract}

Palavras-chave: cooperar; competir; oligopólio; jogos de empresas.

\begin{abstract}
The dilemma faced by oligopolistic price-taking companies was studied - tacit cooperation profitoriented (collusion) or aggressive price competition market-oriented. The results obtained by an experiment based on a Business Game (MMG) produced raw data from a seven-firm oligopoly studied for four years. The descriptive analysis based on Industry Attractiveness, Microeconomic Analysis, Game Theory, and Stakeholders Analysis showed that competition destroyed value for investors (profits were transformed into losses and company share prices fell 23\%) and for the government (less taxes). In contrast, $22 \%$ more consumers were able to buy $22 \%$ more products $10 \%$ cheaper, the number of distribution centers and sales representatives grew twice as much, $21 \%$ more computers were produced, $13 \%$ more employees were hired, and 63\% more investments in technology $(R \& D)$. The results suggest that to neutralize the negative effects of competition and promote sustainable economic growth it is suitable for firms to practice legal ways to engage in coopetition and create a) superior attractiveness for the industry, b) social orientation by improving wages, creating and maintaining jobs, along with c) support for the economy's development with better products, higher GDP and taxes, and strengthening consumer wrights.
\end{abstract}

Key words: cooperation; competition; oligopoly; business games. 


\section{INTRODUÇÃO}

"Entre o branco e o preto há infinitos tons de cinza".

Competir ou cooperar é um dilema sempre atual, estudado por administradores, economistas, matemáticos e cientistas sociais. Apesar de perene, tal conflito não admite solução trivial. Indivíduos, famílias, empresas e nações se têm defrontado com a gangorra do poder, ora dos compradores, ora dos vendedores. Fazer concessões para alcançar acordos, negociar para produzir benefícios mútuos, obter informações para gerar vantagens são táticas que produzem resultados muito distintos: algumas visam à substância negociada - ganhos tangíveis de curto prazo; outras, ao relacionamento entre as partes - ganhos intangíveis de longo prazo.

Nas últimas décadas o ambiente global das empresas apresenta grandes mudanças. Ameaças e oportunidades advindas de fatores estruturais, econômicos e políticos acirram a competição, atraindo novos agentes econômicos. Mesmo as economias desenvolvidas têm de ajustar-se aos novos tempos e às ameaças inesperadas que trazem consigo o fantasma da recessão.

Os oligopólios vivem crises transformadoras. A indústria global de computadores é bom exemplo. Líderes como a IBM, que lideravam o mercado de máquinas de grande porte, são frontalmente ameaçados por desconhecidos fabricantes de microcomputadores, substitutos com desempenho superior, portabilidade e preços incomparavelmente baixos. Outros concorrentes simplesmente sucumbiram diante da competição.

Em economias emergentes como o Brasil, foram marcantes as mudanças. O ambiente dos anos 70, que se organizava com poucos fornecedores, torna-se altamente concorrencial nos anos 90. A estrutura estável de mercado, antes garantida por reservas de mercado e alianças de cooperação, dá lugar à iniciativa individual e acirradas disputas. Enquanto os agentes econômicos aprendem no novo ambiente, os lucros se redistribuem entre os diferentes grupos de interesses, modificando a atratividade dos setores e desafiando as escolhas dos investidores.

Com o objetivo de identificar os benefícios e os beneficiários do valor gerado em um oligopólio, examinou-se neste estudo o efeito, ora da cooperação, ora da competição, para diversos grupos de interesses (stakeholders). Na primeira parte foi apresentada uma revisão conceitual dos modelos que tratam de: a) Atratividade das Indústrias; b) Estruturas de Mercado, c) Teoria dos Jogos e d) Grupos de 
interesses (stakeholders). Foi descrito na segunda parte o experimento laboratorial (Jogo de Empresas), método de pesquisa que produziu os dados primários, submetidos a uma análise descritiva. Os resultados da análise foram discutidos à luz das teorias revisada para produzir algumas conclusões na terceira parte.

\section{Atratividade das Indústrias}

Estudos sobre a estratégia das empresas (Chandler, 1977; Porter, 1985) apontam de maneira recorrente que algumas indústrias são mais atrativas que outras por razões decorrentes da estrutura (da empresa ou do setor) ou da estratégia. Em ambos os casos, a atratividade é medida pelos lucros ou retornos (ex: ROE Return on Equity), descontado o custo de capital (Ke), calculados em relação ao capital investido, que varia substancialmente entre setores.

\section{Tabela 1: Retornos Econômicos Médios de Grupos Setoriais nos EUA, de 1978 a 1996}

\begin{tabular}{|c|c|c|}
\hline Grupo Setorial & ROE-Ke (retorno do capital) & Capital médio investido \\
\hline Produtos farmacêuticos & $15 \%$ & Mínimo pesquisado \\
\hline Computadores e periféricos & $-2 \%$ & Acima da média \\
\hline Companhias Aéreas & $-5 \%$ & Acima da média \\
\hline Aço & $-10 \%$ & Máximo pesquisado \\
\hline
\end{tabular}

Fonte: Adaptado de Ghemawat, 2000, p. 32.

Apesar de perseguirem retornos positivos, diversos setores nos Estados Unidos têm operado por décadas com resultados historicamente negativos (Tabela 1) como é o caso dos Computadores e Periféricos, das Companhias Aéreas e da indústria do Aço.

A Matriz de Atratividade (Ghemawat, 2000, p. 25), modelo para análise de portafólio de investimentos, destaca dois fatores fundamentais: o desempenho da indústria em face do ambiente econômico e a força dos negócios da empresa. Dependendo do nível e da sustentabilidade dos resultados financeiros, recomendase ao gestor uma das quatro alternativas:
a) Investir e crescer.
b) Crescer seletivamente.
c) Selecionar mercados e produtos ou
d) Colher/desinvestir, retirando-se dos negócios. 
Apesar da utilidade dos modelos teóricos, os administradores precisam fazer mais do que reconhecer quão lucrativas são determinadas arenas de concorrência. Devem compreender as razões por trás desses efeitos, para decidir onde e como suas empresas irão competir; avaliar as implicações de mudanças no cenário dos negócios e adaptar-se a elas, ou ainda promover mudanças no ambiente. Tal entendimento é tão desafiador que levou Warren Buffet (Ghemawat, 2000, p. 3143) a afirmar: "quando uma indústria com reputação de dificuldades econômicas encontra gerentes com reputação de excelência, normalmente é a indústria que mantém sua reputação intacta".

Além da matriz de atratividade, foram propostas três estruturas genéricas de análise:

1. A análise oferta-demanda de mercados individuais.

2. A estrutura de 'cinco forças competitivas' para análise de setores proposta por Porter.

3. A 'rede de valor' criada por Adam Brandenburger e Barry Nalebuff.

As duas primeiras são amplamente conhecidas e freqüentemente revisitadas na literatura. A rede de valor amplia as estruturas anteriores e revela a existência de importantes complementadores nas indústrias, agentes influenciadores da atratividade. Um bom exemplo é apresentado para indústria de hardware e software: o sistema operacional Windows 95 da Microsoft é muito mais valioso em um computador equipado com processador Intel Pentium do que em outro contendo um chip 486 e vice-versa. Os complementadores parecem particularmente importantes nas situações em que as empresas estão desenvolvendo maneiras novas de operar. Eles acrescentam uma dimensão cooperativa ao jogo dos negócios, o que pode significar: 'tornar o bolo maior em vez de lutar com os concorrentes por um bolo fixo, desenvolvendo novos complementos ou tornando os atuais mais disponíveis'.

\section{Estruturas de Mercado}

Data da Idade Média a idéia de que a relação oferta-demanda determina um preço natural (Ghemawat, 2000, pp. 33-4). O debate sobre 'valor' promoveu a criação do modelo das 'tesouras de Marshall': seria o 'valor' regido pelos custos - o lado da oferta - ou pela utilidade - o lado da demanda? (Douglas, 1992, p. 363). Concluíram que o preço seria determinado pelo ponto de equilíbrio onde, para determinado produto, a curva da demanda cruza com a curva da oferta. 
Pouco aplicadas até as recessões dos anos 70 e 80, as idéias de Marshall tornaramse gradualmente mais utilizadas na formulação de estratégias, na compreensão dos custos e na determinação do nível de estabilidade dos preços. A teoria clássica dos preços apresenta um modelo para análise de mercados que se baseia em sete premissas (Quadro 1).

\section{Quadro 1: Estruturas de Mercado e suas Sete Premissas}

\begin{tabular}{|c|c|c|c|c|}
\hline Agentes & Tomadores de preços & \multicolumn{3}{|c|}{ Formadores de preços } \\
\hline Estrutura de mercado & Concorrência Pura & Concorrência Monopolista & Oligopólio & Monopólio \\
\hline \multicolumn{5}{|c|}{ Premissas Estruturais } \\
\hline 1. Número de vendedores & Muitos & Vários & Poucos & Um \\
\hline 2. Condições de custo & \multicolumn{4}{|c|}{ No curto prazo, retornos decrescentes na produção } \\
\hline 3. Número de compradores & \multicolumn{4}{|c|}{ Muitos } \\
\hline 4. Condições de demanda & Substitutos idênticos & Substitutos muito similares & $\begin{array}{c}\text { Substitutos } \\
\text { pouco similares }\end{array}$ & $\begin{array}{l}\text { Não há } \\
\text { substitutos }\end{array}$ \\
\hline \multicolumn{5}{|c|}{ Premissas Comportamentais } \\
\hline 5. Objetivos da empresa & \multicolumn{4}{|c|}{ Maximização do lucro no curto prazo } \\
\hline 6. Variáveis estratégicas & Quantidade produzida & \multicolumn{3}{|c|}{$\begin{array}{c}\text { Quantidade produzida; } \\
\text { Preço, promoção, design do produto e canais de distribuição }\end{array}$} \\
\hline $\begin{array}{l}\text { 7. Expectativas quanto às } \\
\text { reações dos concorrentes }\end{array}$ & \multicolumn{2}{|c|}{ Nenhuma } & $\begin{array}{l}\text { Dependem dos } \\
\text { objetivos dos } \\
\text { concorrentes }\end{array}$ & Nenhuma \\
\hline
\end{tabular}

Fonte: Adaptado de Douglas (1992, p. 363).

Na concorrência pura ou perfeita (Quadro 1), um número elevado de empresas produz bens idênticos em ambiente de simetria informacional, ou seja, todas as empresas sabem onde comprar insumos baratos e todos os consumidores onde comprar produtos baratos (ex: estrutura teórica ideal). Na concorrência monopolista ou imperfeita, várias empresas competem com produtos diferenciados, embora substitutos próximos (ex: cigarros, refrigerantes e sabonetes). No oligopólio, que prevalece no Brasil, há um número pequeno de empresas cujos produtos são diferenciáveis, de acordo com preços, quantidades produzidas, modelos, esforços promocionais e pontos de venda (ex: transporte aéreo, rodoviário, química, siderurgia e microcomputadores). No monopólio o setor é a própria firma, pois há um único vendedor sem produtos substitutos (Spínola \& Troster, 1998, p. 182).

Firmas operando em regime de concorrência pura são 'tomadoras de preços', definidos pelo equilíbrio entre oferta e demanda. Quando operam em mercados imperfeitos (concorrência monopolística, oligopólio ou monopólio) tornam-se 'formadoras de preços' e podem ajustá-los segundo seus interesses. Nestas, a assimetria informacional constitui fonte de poder.

Quando se estuda um mercado, busca-se identificar o preço e a quantidade em situação de equilíbrio (Pindyck \& Rubinfeld, 1994, p. 561). Num mercado de concorrência pura encontra-se o preço de equilíbrio, quando as quantidades ofertadas e demandadas são iguais. Para os agentes ofertantes, quando a curva 
da demanda é idêntica à da receita marginal, o lucro econômico tende a zero. O equilíbrio num monopólio ocorre, quando a receita marginal se iguala ao custo marginal, anulando o lucro incremental. Como neste caso as curvas de demanda e de receita marginal são diferentes, o monopolista obtém lucros econômicos positivos com um preço de equilíbrio superior ao da concorrência pura, resultando quantidades demandadas inferiores. Na concorrência monopolista, o equilíbrio no longo prazo ocorre, quando novas empresas entram no mercado, forçando os lucros a zero. Nesses mercados, cada empresa assume como premissa o preço ou a demanda, sem preocupar-se com os concorrentes. No mercado oligopolista a empresa determina preço e volume com base na expectativa de comportamento dos concorrentes.

\section{TEORIA DOS JOGOS}

Surge em 1944 de autoria do matemático John von Neumann e do economista Oskar Morgenstern a fundamental publicação do livro 'Teoria dos Jogos e comportamento econômico', uma aplicação matemática à teoria econômica. Para os economistas, um jogo é caracterizado por um conjunto de regras que descrevem a realidade, definindo os agentes econômicos (jogadores), as possíveis ações (estratégias) dos agentes econômicos e um conjunto informações que orientam os agentes nas decisões racionais e maximizadoras de resultados (Gremaud \& Braga, 1998, pp. 246-247).

As soluções mais conhecidas em jogos de estratégia são: a) dominância, b) maxmin, e c) o equilíbrio de Nash. Uma estratégia é dominante em relação às demais, quando os resultados obtidos na sua adoção são os melhores, quaisquer que sejam as ações dos demais jogadores. Quando não há uma estratégia dominante, o jogador pode maximizar o mínimo resultado que pode assegurar para si, sem depender dos demais jogadores. A estratégia de Nash, também conhecida como a de não arrependimento, produz o melhor resultado, dependendo dos demais jogadores. Trata-se do equilíbrio em jogos de soma variável, não cooperativos e com mais de duas pessoas, aplicáveis em estudos de oligopólios (Pindyck \& Rubinfeld, 1994, p. 561): "Cada empresa faz o melhor que pode em função daquilo que fazem seus concorrentes".

A teoria divide-se em dois ramos: jogos cooperativos e não cooperativos (Kreps, 1990, p. 9). Nos cooperativos, os participantes desejam maximizar o resultado da coalizão e para isso colaboram uns com os outros (Quadro 2). Nos não cooperativos, a unidade de análise é o indivíduo que se preocupa em maximizar seus próprios resultados, dentro das regras do jogo, qualquer que seja o resultado coletivo. $\mathrm{Na}$ 
prática a cooperação ficaria bastante facilitada, se proporcionasse o melhor resultado individual e também coletivo.

\title{
Quadro 2: Jogos Cooperativos versus Jogos Não Cooperativos
}

\begin{tabular}{|l|l|l|}
\hline Ramos da Teoria dos Jogos & Unidade de análise & Objetivo do jogador \\
\hline Jogos cooperativos & Grupo ou coalizão & Maximizar os resultados do grupo \\
\hline Jogos não cooperativos & Indivíduo isolado & Maximizar os resultados individuais \\
\hline
\end{tabular}

Fonte: Adaptado de Kreps (1990, p. 9).

O exemplo clássico da aplicação da Teoria dos Jogos e que ilustra seus desdobramentos denomina-se Dilema dos Prisioneiros e descreve bem o conflito das empresas oligopolistas:

\begin{abstract}
"Dois prisioneiros são acusados de terem cooperado durante um crime. Estão incomunicáveis em celas diferentes. Foi solicitada a confissão do crime a cada um. Se confessarem, ambos serão condenados a cinco anos de prisão. Se um deles confessar e o outro não, aquele que confessou terá sua pena reduzida para um ano. $\mathrm{O}$ outro será condenado a dez anos de prisão. Se nenhum deles confessar, ambos poderão apelar pela redução das penas de cinco para dois anos (Quadro 3). Se você fosse um dos prisioneiros, qual seria sua opção: confessar ou não confessar?"
\end{abstract}

Fonte: Adaptado de Pindyck e Rubinfeld, 1994, p. 581.

Na Matriz de Decisões dos prisioneiros (Quadro 3) a soma das penas dos prisioneiros difere em cada uma das células e indica não se tratar de 'jogo de soma zero' (o ganho de um não se resume à perda do outro). Embora os exemplos relacionados à Teoria dos Jogos abordem dois competidores, o jogo com mais participantes é mera generalização (Owen, 1995, p. 212).

\section{Quadro 3: Matriz de Decisões e Resultados do Dilema dos Prisioneiros}

\begin{tabular}{|c|c|c|c|c|c|}
\hline & \multicolumn{5}{|c|}{ Prisioneiro B } \\
\hline \multirow{3}{*}{ Prisioneiro A } & Decisões possíveis & \multicolumn{2}{|c|}{ Confessa } & \multicolumn{2}{|c|}{ Não Confessa } \\
\hline & Confessa & $-5(\mathrm{~A})$ & $-5(\mathrm{~B})$ & $-1(\mathrm{~A})$ & $-10(\mathrm{~B})$ \\
\hline & Não Confessa & $-10(\mathrm{~A})$ & $-1(\mathrm{~B})$ & $-2(\mathrm{~A})$ & $-2(\mathrm{~B})$ \\
\hline
\end{tabular}

Fonte: Pindyck e Rubinfeld, 1994, p. 581.

Empresas oligopolistas vivem este dilema: 'competir' para aumentar sua fatia de mercado ou 'cooperar' tacitamente para obter lucros aceitáveis. Tornam-se passivas ao cooperar, limitam sua produção e praticam preços mais elevados, obtendo lucros maiores. 
Tal qual o dilema dos prisioneiros, a empresa que tacitamente participa de um conluio poderá sentir-se tentada a 'trair o acordo tácito' e praticar preços menores, temendo ação semelhante dos concorrentes. Por melhor que pareça a cooperação, cada empresa preocupa-se com a idéia de que, ao operar passivamente sob acordo tácito, seus concorrentes atuem agressivamente, conquistando maior fatia do mercado. Com o passar do tempo, a cooperação torna-se duvidosa e induz a competição que, segundo Nash, produz novo equilíbrio com lucros menores. Enquanto no dilema dos prisioneiros a decisão ocorre uma única vez, no jogo real das empresas as decisões sobre quantidades a produzir, preços a praticar e investimentos a realizar repetem-se continuamente, afetam o equilíbrio no curto prazo e interferem nas decisões futuras dos concorrentes. Neste novo contexto de lucros menores, a cooperação volta a ser cogitada como alternativa possível.

O cientista político Robert Axelrod (como citado em Pindyck \& Rubinfeld, 1994, p. 625), no final dos anos 70, denomina tit-for-tat a estratégia mais robusta ou dominante, aquela que em média funciona melhor nos jogos repetitivos - 'olho por olho, dente por dente'. Sua lógica é simples: a cooperação abre o jogo; a seguir repete-se cada movimento do outro jogador (Nowak, 2000, p. 15). Esta estratégia induz a cooperação. Se o oponente deixa de cooperar, cessa a cooperação até que ele recue. De forma similar, quando dois concorrentes, empresa 1 e empresa 2 se percebem como racionais; para um número finito de repetições desenha-se outro cenário (Pindyck \& Rubinfeld, 1994, p. 625) em que cada um raciocina da seguinte maneira:

Pelo fato de a empresa 1 estar praticando a estratégia tit-for-tat, a empresa 2 não deverá vender por menos até o penúltimo período. Poderá fazê-lo somente no último período para realizar lucros mais altos, já que o jogo estará terminando e não haverá tempo para retaliações. Pensa a empresa 2: "venderemos por menos somente no último período". Considerando que a empresa 1 poderá ter a mesma idéia, também reduzirá o preço no último período. Contudo, como ficaria o penúltimo período? A empresa 2 deveria vender por menos no penúltimo período, já que poderá não haver cooperação no último período. Como ambas já terão pensado nesta possibilidade, estariam planejando cobrar menos no penúltimo período. O mesmo raciocínio é aplicável a cada mês precedente e a única alternativa a ambas seria praticarem o preço mais baixo em todos os períodos.

Obs: preço mais alto= cooperação; preço mais baixo= competição.

Para Nash, a combinação de estratégias escolhidas leva a um resultado em que nenhum dos jogadores se arrepende, ou seja, cada jogador não poderia melhorar 
sua posição unilateralmente simplesmente modificando sua estratégia. Numa situação em que se utiliza o conceito de Nash, um jogador escolhe a melhor estratégia, dada a escolha do outro jogador.

Existe uma dependência característica nos oligopólios que condiciona a estratégia de cada empresa em função dos concorrentes. Esta definição ajuda a estudar e entender os mercados imperfeitos, caracterizados no Quadro 4:

\section{Quadro 4: Características e Assimetrias em Mercados Imperfeitos}

\begin{tabular}{|c|c|}
\hline Características dos Mercados Imperfeitos & Assimetrias observadas \\
\hline Pequeno número de competidores & Ações sigilosas entre os competidores \\
\hline Informações limitadas sobre o mercado & Contratos incompletos \\
\hline Possibilidade de interações não mercadológicas & Relações de agência (conflito de interesses) \\
\hline
\end{tabular}

Fonte: adaptado de Nowak, 2000, p. 13.

Tomando-se o conceito proposto por Nash e considerando que um competidor não é 100\% racional, surgem duas situações de equilíbrio em jogos repetitivos: cooperação nas rodadas iniciais; competição nas rodadas finais. Quanto mais cedo o jogador deixa de cooperar, maior será o grau de racionalidade (Kreps, Milgrom, Roberts, \& Wilson, 1982, pp. 245-52).

A estratégia de Nash foi aqui escolhida para o estudo de um oligopólio, porque reflete a atitude dos alunos de pós-graduação da FEA/USP/SP que atuavam em um Jogo de Empresas. Examina o desempenho de 7 fabricantes que buscaram obter o melhor resultado em função das ações dos concorrentes, visto que tal desempenho valia nota para a aprovação. Por esta razão tal estratégia mostra-se a mais adequada para examinar os benefícios produzidos e sua distribuição aos beneficiários, na cooperação e na competição.

\section{Relações com os Grupos de Interesses (STAKEHolders)}

Apesar de a questão estrutural explicar uma parcela do desempenho das indústrias e dos vendedores que nelas operam, os benefícios particulares alcançados pelas empresas diferem de uma para outra de acordo com suas estratégias. Ao formulá-las o gestor as adapta às expectativas dos grupos que representa. Dada a diversidade de stakeholders e respectivos interesses, tornamse inúmeros os conflitos decorrentes.

A responsabilidade social das empresas impõe obrigações que vão além da maximização dos lucros. Como as empresas podem ser muito poderosas, elas 
deveriam retribuir à sociedade, assumindo responsabilidades sociais. Na prática isto representa especial atenção aos clientes, fornecedores, empregados e comunidade local, além dos tradicionais acionistas. Entretanto Friedman e seus discípulos postulavam (Silbiger, 1996, p. 52): “as empresas estão empenhadas em maximizar o valor dos acionistas, pelo uso prudente de recursos organizacionais escassos, desde que as atividades da empresa estejam de acordo com a lei". Caberia, portanto, ao governo, representando a sociedade, determinar as leis mais apropriadas que levassem em conta que uma empresa lucrativa beneficia a sociedade ao criar empregos, aumentar o padrão de vida de seus donos e de seus empregados. Tal empresa paga os impostos que mantêm, por sua vez, a ação social do governo.

Quando se analisa os diferentes grupos de interesses, deve-se estabelecer uma base por meio da qual se pode organizar os diversos pensamentos. Qualquer ato gerencial produz ganhos e perdas aos envolvidos, o que evidencia direitos e responsabilidades. A análise dos envolvidos (stakeholders) é adotada para classificar os aspectos críticos, reduzindo-se uma longa lista aos mais importantes. Por fim, uma análise situacional orienta o encadeamento da decisão.
a) Elenco de personagens
b) Danos e benefícios para cada participante
c) Direitos e responsabilidades
d) Poder relativo de cada parte
e) Conseqüências no curto e no longo prazo das alternativas de decisão
f) Planos de contingência para cenários alternativos
g) Julgamento e escolha

A responsabilidade social, o retorno ao acionista e outras correntes de pensamento têm orientado a gestão das organizações. No utilitarismo, por exemplo, afirma-se que 'uma ação é justificada se proporcionar o máximo de benefícios ao maior número de pessoas'. Qualquer que seja a filosofia adotada, existirão sempre expectativas, tensões e posturas dos envolvidos que dinamicamente tomam decisões em busca de resultados (Quadro 5). 


\section{Quadro 5: Expectativas dos Grupos de interesses}

\begin{tabular}{|c|c|c|}
\hline Grupos de Interesses & Decisões & Resultados esperados \\
\hline Acionistas & Investir / desinvestir & Maior preço da ação; dividendos. \\
\hline Consumidores & Consumir / Não consumir & Satisfação de necessidades \\
\hline Fornecedores & Fornecer / Não fornecer & Crescimento das vendas \\
\hline Gestores & Competir / cooperar & Lucros; satisfação dos stakeholders \\
\hline Governo & Observar / Intervir & Desenvolvimento sustentável \\
\hline Trabalhadores & Trabalhar / Fazer greve & Renda \\
\hline
\end{tabular}

\section{Problema de Pesquisa}

O problema de pesquisa foi formulado sobre as quatro bases conceituais apresentadas acima:

1) Modelo de Atratividade da Indústria em que se examina o desempenho da estratégia.

2) Estrutura da indústria oligopolizada com 7 fabricantes de computadores.

3) Solução de Nash ao problema de estratégia em um jogo seqüencial, onde cada empresa faz o melhor que pode, dependendo das ações dos concorrentes.

4) Redistribuição assimétrica dos resultados para os diferentes grupos de interesses.

O conflito cooperar-competir será examinado por meio da premissa de que, em jogos seqüenciais com número finito de rodadas em um mercado oligopolista, verifica-se que:

H01: A competição livre em um oligopólio não reduz os lucros totais da indústria, quando comparados aos lucros totais produzidos sob regime de cooperação.

Tal premissa é pertinente e se aplica à situação em estudo (Sauaia \& Kallás, 2003, 2004). Apesar de a abertura e a privatização da economia brasileira terem estimulado a livre iniciativa, a concorrência tem sido positiva em alguns setores e predatória em outros. A viabilidade econômica de um país depende da atratividade de suas indústrias em que as empresas possam competir de maneira sustentável e, ao mesmo tempo, atender aos anseios de diferentes stakeholders. 


\section{Método de Pesquisa}

Ao contrário dos estudos de caso em que se analisam dados secundários, para o experimento aqui relatado foram gerados dados primários, num ambiente empresarial simulado, por meio de um Jogo de Empresas computadorizado. Tratase de um jogo de simulação, voltado ao mundo dos negócios, utilizado em treinamento e desenvolvimento gerencial, na avaliação de potencial, em planejamento estratégico, na tomada de decisões em caráter experimental e na formação de administradores (Sauaia, 1997). Tem crescido o número de publicações em que se adotaram os jogos de empresas como método de pesquisa. Faria (2000, p. 90) destaca algumas aplicações em pesquisa:

. Práticas (vivências) que estimulam a melhoria no desempenho gerencial

. Estudos sobre a efetividade dos jogos de empresas

. Estudos sobre a aprendizagem propiciada pelos jogos de empresas.

\section{DESCRIÇÃO DO EXPERIMENTO}

Neste estudo discute-se a estrutura, as operações e os resultados das estratégias numa indústria de microcomputadores modelada em um Jogo de Empresas. Foi criado um laboratório com o simulador MMG - Multinational Management Game, do tipo Total Enterprise (TE) (classificação da ABSEL - Association for Business Simulation and Experiential Learning), que engloba todas as áreas funcionais de uma organização e proporciona um exercício sistêmico de tomada de decisões (Keys, Edge, \& Wells, 1992). Simula empresas que operam num segmento da indústria global de computadores, com sede nos Estados Unidos (mercado doméstico), podendo operar na Europa (Alemanha) e Ásia (Malásia). Produzem e comercializam dois produtos: microcomputadores (bem de consumo final) e placas de memória para microcomputadores (bem intermediário). Um ciclo de decisão equivale a um ano de operações, conferindo ao jogo um caráter estratégico. O MMG simula uma típica estrutura de mercado oligopolista com poucos competidores (até 8 empresas), onde as ações de uma empresa afetam as demais empresas, sendo possível diferenciar o produto de acordo com preço, promoção, design (pesquisa e desenvolvimento) e canais de distribuição.

A conjuntura econômica apresenta crescimento médio anual entre 4\% e 5\% e inflação entre 3\% e 5\%. As decisões anuais aglutinam-se em três áreas (Quadro 6) de estratégia da empresa. 


\section{Quadro 6: Variáveis do Ciclo Anual de Decisões - MMG - Multinational Management Game}

\begin{tabular}{|l|l|}
\hline Áreas de decisão & Variáveis de decisão \\
\hline \multirow{5}{*}{ Decisões de Marketing } & Preço do produto A (bem de consumo) \\
\cline { 2 - 2 } & Preço do produto B (bem intermediário) \\
\hline & Gastos com propaganda \\
\hline & Número de representantes de venda \\
\hline & Percentual de comissão de vendas \\
\hline & Gastos com pesquisa e desenvolvimento \\
\hline & Centros de Distribuição \\
\hline Decisões de Operações & Número total de estações de trabalho para o próximo ano \\
\hline & Empregados programados para produção regular - produto A \\
\hline & Empregados programados para produção regular - produto B \\
\hline & Empregados programados para produção com horas extras - produto A \\
\hline & Empregados programados para produção com horas extras - produto B \\
\hline & Salário por hora da mão-de-obra \\
\hline Decisões Financeiras & Alterações na dívida de longo prazo \\
\hline & Montante de dividendos pagos \\
\hline & Compra ou venda de ações \\
\hline & Outras Despesas \\
\hline
\end{tabular}

\section{Ambiente da Cooperação}

Neste ambiente simulado em laboratório sem o envolvimento de jogadores, as sete empresas adotam, tacitamente, as mesmas decisões nas três áreas estratégicas e cooperam por quatro anos consecutivos (Anos 1 a 4). Configurase 'uma competição passiva' (coalizão), semelhante ao comportamento de um monopólio, nas seguintes bases.

- Preços dos Produtos A e B. As empresas mantêm os preços praticados no ano zero (situação inicial), corrigidos anualmente pelo índice de inflação.

. Gastos com propaganda, pesquisa \& desenvolvimento e salário dos empregados. Todos os vendedores mantêm os níveis históricos, corrigidos pela inflação.

- Número de centros de distribuição, representantes de vendas e comissão dos vendedores. Manutenção inalterada da estrutura inicial de distribuição e comercialização.

. Quantidades produzidas. As empresas assumem postura reativa, produzindo conforme a demanda prevista e investindo em aumento de capacidade somente se houver crescimento do mercado resultante das decisões mercadológicas. Não são programadas horas extras. 
. Outras despesas. Considera-se uma contribuição anual para a uma entidade setorial, responsável por promover e facilitar a cooperação entre as empresas.

\section{AMbiente da Competição}

Um ou dois alunos regulares de pós-graduação stricto sensu em 2001 na FEA/ USP/SP livremente organizados, operaram as sete empresas em ambiente doméstico por quatro anos, partindo da mesma situação inicial. A cada aula de 4 horas eram tomadas decisões para um ou dois anos de operações. A competição foi fortemente estimulada pela promessa de que $50 \%$ da avaliação final da disciplina estaria vinculada aos resultados de sete indicadores de desempenho das empresas (múltiplos setoriais), induzindo a adoção da estratégia proposta por Nash: fazer o melhor possível (desempenho), dependendo do que fizerem os concorrentes.

Em uma rodada experimental, cujos resultados não foram computados na avaliação, cada grupo testou a sensibilidade das variáveis da simulação e familiarizou-se com a dinâmica do exercício, o que contribuiu ainda mais para a assimetria informacional.

\section{Quadro 7: Características do Contexto da Competição}

\begin{tabular}{|ll|}
\hline \multicolumn{2}{|c|}{ Condições do Oligopólio para a Diferenciação e a Competição } \\
\hline a) & Livre formação de grupos; assimilação assimétrica do problema inicial idêntico. \\
\hline b) & Livre arbítrio dos grupos para a tomada de decisões \\
\hline c) & Avaliação do jogo baseada no desempenho de 7 múltiplos setoriais \\
\hline d) & Realização de uma rodada experimental para teste de mercado e da sensibilidade do jogo \\
\hline e) & Liberdade para a criação do próprio sistema de apoio à decisão para cada empresa \\
\hline f) & Assimetria informacional, face à possibilidade de aquisição de relatórios da indústria e dos concorrentes. \\
\hline
\end{tabular}

Numa sala com microcomputadores (laboratório), cada grupo preparou seu sistema de apoio à decisão, operado em planilha eletrônica. A partir da terceira rodada, as equipes puderam reforçar seu sistema de inteligência competitiva comprando, a preços elevados, relatórios com dados da indústria e concorrentes. Apesar de as condições apresentadas promoverem a competição, houve momentos de cooperação, quando o administrador do jogo (professor) se ausentou da sala. Outros aspectos do contexto da competição estão descritos no Quadro 7.

\section{Análise Descritiva dos Resultados}

As tabelas apresentadas a seguir trazem a comparação entre os resultados mercadológicos, operacionais e financeiros produzidos na cooperação e na competição. O impacto das ações gerenciais sobre os resultados para cada grupo 
de interesse foi examinado em base percentual. A competição produziu simultaneamente ganhos e perdas para os acionistas (Tabela 2).

\section{Tabela 2: Impactos para os Acionistas}

\begin{tabular}{|c|c|c|c|c|}
\hline \multirow{2}{*}{ Impactos } & \multicolumn{4}{|c|}{ Acionistas } \\
\hline & Indicadores & Cooperação & Competição & Efeito competição \\
\hline \multirow{3}{*}{$\begin{array}{c}\text { Ações } \\
\text { gerenciais }\end{array}$} & Lucro líquido (total da indústria: valor presente) & $\$ 643,657$ & $(\$ 81,536)$ & $-112.7 \%$ \\
\hline & Dividendos pagos (\$ mil a valor presente) & $\$ 42,000$ & $\$ 66,981$ & $59.5 \%$ \\
\hline & Quantidade de ações em circulação (mil) & 875,000 & 925,000 & $5.7 \%$ \\
\hline \multirow[t]{2}{*}{ Resultados } & Preço da ação (média a valor presente) & $\$ 7.19$ & $\$ 5.53$ & $-23.0 \%$ \\
\hline & Valor médio de Mercado das empresas (mil) & $\$ 6,288,494$ & $\$ 5,119,741$ & $-18.6 \%$ \\
\hline
\end{tabular}

Os dividendos totais pagos foram 59,5\% maiores na competição. Entretanto o preço médio da ação foi $23 \%$ menor, em face do número de ações em circulação $5,7 \%$ maior, e ao lucro total da indústria 112,7\% menor. Foi reduzido em 18,6\% o valor médio de mercado das empresas.

\section{Tabela 3: Impactos para os Consumidores}

\begin{tabular}{|c|l|r|r|c|}
\hline \multirow{2}{*}{ Impactos } & \multicolumn{4}{|c|}{ Consumidores } \\
\cline { 2 - 5 } & \multicolumn{1}{|c|}{ Indicadores } & Cooperação & Competição & Efeito competição \\
\hline \multirow{4}{*}{$\begin{array}{c}\text { Ações } \\
\text { gerenciais }\end{array}$} & Preço do produto A (média a valor presente) & $\$ 1,600$ & $\$ 1,449$ & $-9.4 \%$ \\
\cline { 2 - 5 } & Preço do produto B (média a valor presente) & $\$ 225$ & $\$ 196$ & $-12.8 \%$ \\
\cline { 2 - 5 } & Total de vendedores (media annual) & 560 & 1,117 & $99.4 \%$ \\
\cline { 2 - 5 } & Total de Centros de distribuição (media anual) & 35 & 75 & $112.9 \%$ \\
\cline { 2 - 5 } & Gastos com Pesquisa e Desenvolvimento & $\$ 280,000$ & $\$ 456,904$ & $63.2 \%$ \\
\cline { 2 - 5 } & Demanda total de A em unidades & $3,504,249$ & $4,272,645$ & $21.9 \%$ \\
\hline \multirow{3}{*}{ Resultados } & Demanda total de B em unidades & $3,504,067$ & $4,603,723$ & $31.4 \%$ \\
\cline { 2 - 5 } & Vendas perdidas de A (total de unidades) & - & 179,286 & $4,2 \%$ \\
\cline { 2 - 5 } & Vendas perdidas de B (total de unidades) & $-71,038$ & $1,5 \%$ \\
\hline
\end{tabular}

Para os consumidores, a competição foi positiva (Tabela 3). Preços menores, qualidade do produto maior (gastos com P\&D) e maior capilaridade da distribuição (mais centros de distribuição e vendedores ativos) impulsionaram o mercado, elevando as vendas. $\mathrm{O}$ ambiente competitivo proporcionou maior acesso dos consumidores aos produtos de consumo, elevando a demanda em $22 \%$ para o produto A e $32 \%$ para o produto $\mathrm{B}$. Isto se deveu a preços $10 \%$ menores para o produto $\mathrm{Ae} 13 \%$ menores para o produto $\mathrm{B}$, à duplicação do número de vendedores e de $112 \%$ mais CDs. Tal estímulo provocou demanda reprimida do produto de consumo A $(4,2 \%)$ e do produto industrial B (1,5\%) e ineficiência mercadológica.

\section{Tabela 4: Impactos para os Fornecedores}

\begin{tabular}{|c|c|c|c|c|}
\hline \multirow{2}{*}{ Impactos } & \multicolumn{4}{|c|}{ Fornecedores } \\
\hline & Indicadores & Cooperação & Competição & Efeito da competição \\
\hline \multirow{3}{*}{$\begin{array}{c}\text { Ações } \\
\text { gerenciais }\end{array}$} & Compra matéria prima: produto A (em unidades) & $3,593,100$ & $4,347,112$ & $21.0 \%$ \\
\hline & Compra matéria prima: produto B (em unidades) & $5,191,200$ & $5,425,118$ & $4.5 \%$ \\
\hline & Workstations adquiridas (total em unidades) & 700 & 1,900 & $171.4 \%$ \\
\hline Resultados & Juros pagos (total em \$ mil a valor presente) & $\$ 175,422$ & $\$ 343,574$ & $95.9 \%$ \\
\hline
\end{tabular}


Os fornecedores foram fartamente beneficiados na competição. Foram adquiridas (Tabela 4) mais matérias-primas, $21 \%$ para A e $4,5 \%$ para B, mais $171 \%$ estações de trabalho e contrataram-se mais $96 \%$ em empréstimos.

A competição prejudicou os indicadores econômico-financeiros das empresas (Tabela 5). O retorno médio sobre ativos de $11 \%$ no ambiente da cooperação torna-se negativo (-1,82\%), registrando queda de $116,6 \%$. O lucro de $\$ 644$ milhões das sete empresas (ano 1 ao 4) trazido a valor presente pela inflação, torna-se prejuízo de $\$ 82$ milhões.

Tabela 5: Impactos para as Empresas

\begin{tabular}{|c|c|c|c|c|}
\hline \multirow[t]{2}{*}{ Impactos } & \multicolumn{4}{|c|}{ Gestores } \\
\hline & Indicadores & Cooperação & Competição & Efeito competição \\
\hline \multirow{4}{*}{$\begin{array}{c}\text { Resultados } \\
\text { econômico } \\
\mathrm{e} \\
\text { financeiro }\end{array}$} & Lucro líquido (total indústria: valor presente $\mathrm{x} 1.000$ ) & $\$ 643,657$ & $(\$ 81,536)$ & $-112.7 \%$ \\
\hline & Retorno sobre o Investimento (médio) & $10.64 \%$ & $-0.34 \%$ & $-103.2 \%$ \\
\hline & Retorno sobre Vendas (médio) & $10.00 \%$ & $-5.32 \%$ & $-153.2 \%$ \\
\hline & Retorno sobre o Ativo (médio) & $11.00 \%$ & $-1.82 \%$ & $-116.6 \%$ \\
\hline \multirow{2}{*}{$\begin{array}{l}\text { Resultado } \\
\text { operacional }\end{array}$} & Produtividade de A (média em unidades) & 165 & 168 & $1.7 \%$ \\
\hline & Produtividade de B (média em unidades) & 646 & 660 & $2.1 \%$ \\
\hline
\end{tabular}

$\mathrm{Na}$ área operacional (Tabela 6), cresceram os investimentos em Pesquisa e Desenvolvimento (63\%) e os trabalhadores contratados (100\% mais vendedores; $13 \%$ mais operários). Observaram-se (tabela 5) pequenos ganhos na produtividade ( $1,7 \%$ no produto $\mathrm{A}$ e $2,1 \%$ no produto $\mathrm{B})$.

\section{Tabela 6: Impactos para os Operários e Representantes de Vendas}

\begin{tabular}{|c|c|c|c|c|}
\hline \multirow[t]{2}{*}{ Impactos } & \multicolumn{4}{|c|}{ Trabalhadores e Representantes de vendas } \\
\hline & Indicadores & Cooperação & Competição & Efeito competição \\
\hline \multirow{4}{*}{$\begin{array}{c}\text { Ações } \\
\text { gerenciais }\end{array}$} & Salário de vendedores (média a valor presente) & $\$ 42,727$ & $\$ 62,303$ & $45.8 \%$ \\
\hline & Gastos com P\&D (\$mil a valor presente) & $\$ 280,00$ & $\$ 456,904$ & $63,2 \%$ \\
\hline & Salário dos operários (média a valor presente) & $\$ 13.47$ & $\$ 13.51$ & $4.5 \%$ \\
\hline & Número de operários em Horas Extras (média) & & 280 & - \\
\hline Resultados & Turnover e absenteísmo (média) & $7.50 \%$ & 7.25 & $-3.3 \%$ \\
\hline
\end{tabular}

Os trabalhadores - operários e vendedores - beneficiaram-se com a competição (Tabela 6). Houve melhoria nas condições de trabalho (gastos com P\&D elevaram tecnologia do processo e a produtividade dos operários) com salários 4,5\% maiores, maior oferta de empregos e renda média aumentada devido à programação de horas extras, pagas com $50 \%$ de acréscimo. O salário médio dos vendedores foi $45,8 \%$ maior no ambiente competitivo.

Foram antagônicos os impactos nos indicadores sociais e tributários do governo (Tabela 7). A competição gerou mais empregos (12,6\% mais operários e 99,4\% mais vendedores). Com salários médios maiores, a renda dos trabalhadores foi 
24\% superior. Como a maioria das empresas apresentou prejuízos contábeis na competição, o montante de restituições foi superior ao de impostos pagos. $\mathrm{O}$ simulador, entretanto, não opera com outros impostos, como os pagos pelos fornecedores, operários e vendedores, além dos impostos em cascata, presentes no contexto brasileiro. Tal simplificação limita as conclusões, uma vez que a consideração de impostos sobre o valor agregado poderia, em outros modelos, suavizar este impacto. A indústria agregou $102 \%$ de contribuição para o crescimento e a geração de riqueza nacional, em oposição à devastadora perda tributária para os cofres públicos.

\section{Tabela 7: Impactos para o Governo}

\begin{tabular}{|c|c|c|c|c|}
\hline \multirow[t]{2}{*}{ Impactos } & \multicolumn{4}{|c|}{ Governo } \\
\hline & Indicadores & Cooperação & Competição & Efeito competição \\
\hline \multirow{4}{*}{$\begin{array}{l}\text { Ações } \\
\text { gerenciais }\end{array}$} & Total de vendedores (média anual) & 560 & 1,117 & $99.4 \%$ \\
\hline & $\begin{array}{l}\text { Salários pagos aos vendedores } \\
\text { (\$mil total da indústria a valor presente) }\end{array}$ & $\$ 95,709$ & $\$ 275,874$ & $188.2 \%$ \\
\hline & Total de operários (média anual) & 7,700 & 8,670 & $12.6 \%$ \\
\hline & $\begin{array}{l}\text { Salários pagos aos operários } \\
\text { (\$mil total da indústria a valor presente) }\end{array}$ & $\$ 942,900$ & $\$ 1,016,832$ & $7.8 \%$ \\
\hline \multirow[t]{3}{*}{ Resultados } & $\begin{array}{l}\text { Impostos pagos ou restituídos } \\
\text { (total a valor presente) }\end{array}$ & $\$ 331,609$ & $\$(42,002)$ & $95.9 \%$ \\
\hline & Vendas da indústria (em $\$$ mil a valor presente) & $\$ 6,394,451$ & $\$ 6,773,216$ & $5.9 \%$ \\
\hline & $\begin{array}{l}\text { Contribuição para a atividade econômica } \\
\text { (\$mil a valor presente) }\end{array}$ & $\$ 25,062,474$ & $\$ 50,642,295$ & $102.1 \%$ \\
\hline
\end{tabular}

\section{Discussão}

Os resultados aqui apresentados mostram que a competição destruiu valor para o acionista, rejeitando-se a hipótese H01. Em decorrência, o governo também perde arrecadação. O valor se desloca das empresas para as mãos de outros beneficiários que gostariam de ver perpetuadas as disputas de mercado: consumidores, colaboradores e fornecedores. Tais perdas unilaterais parecem induzir empresas oligopolistas a cooperarem por melhores lucros. Entretanto a decisão de cooperar ou competir não é tão simples nem unilateral. Ações cooperativas em oligopólios podem ser interpretadas como atos ilegais, sujeitos a sanções judiciais e a multas que podem variar de $1 \%$ a $30 \%$ do valor das vendas. Este foi o caso de um suposto cartel articulado entre as empresas Telefônica, Brasil Telecom e Telemar para a compra da Embratel, amplamente noticiado na imprensa brasileira em Abril/2004 (Zimmermann, 2004).

A SDE (Secretaria de Direito Econômico do Ministério da Justiça) abriu investigação quanto à associação firmada entre a Telefônica, a Telemar e a Brasil Telecom, com a intenção de analisar a documentação apreendida pela 
polícia. Os documentos apreendidos na sede da Telefônica, em São Paulo, mencionavam estratégia para, no futuro, elevar as tarifas cobradas pela Embratel pelo teto. Pelo acordo secreto, sem a concorrência da Embratel, as teles fixas poderiam reduzir os descontos em vigor e, assim, ampliar o valor das tarifas. A busca foi autorizada pela polícia com base em um inquérito sobre a falência da empresa Cobra SP, prestadora de serviços na área de telefonia. Barbara Rosenberg, diretora do Departamento de Proteção e Defesa Econômica da SDE, informou que quando há diligências policiais relacionadas a casos sob investigação no órgão, o acesso à documentação apreendida é facultado à secretaria. Feita a análise técnica, a SDE decidirá o que é relevante e precisará ser agregado à sua investigação sobre o negócio firmado entre as empresas de telefonia fixa, tendo em vista a compra da Embratel. A investigação começou no mês de fevereiro em decorrência de denúncia encaminhada à SDE pelas entidades Fittel (Federação Interestadual dos Trabalhadores em Telefonia) e Telecomp (Associação Brasileira das Prestadoras de Serviços de Telecomunicações Competitivas), que acusaram a Telefônica, a Brasil Telecom e a Telemar de formação de cartel (Zimmermann, 2004).

\section{Anatel e ministério}

O ministro das Comunicações, Eunício Oliveira, disse que cabe à Anatel (Agência Nacional de Telecomunicações) se manifestar sobre a articulação de empresas para subir preços. Ressaltou sua posição para que "haja ampliação da concorrência para beneficiar o consumidor, seja prestando um bom serviço, seja diminuindo preços". Oliveira se recusou a comentar especificamente o documento apreendido pela polícia que mostra que três empresas de telefonia fixa desejam comprar a Embratel para alinhar as "tarifas pelo teto". "Cabe às autoridades competentes investigar e se manifestar sobre esse episódio específico", afirmou. Oliveira lembrou que "o processo de licitações, de outorga e de fiscalização dos contratos" está a cargo da agência reguladora, no caso, a Anatel. Procurado por meio da assessoria de imprensa, o presidente da Anatel, Pedro Jaime Ziller, não quis se manifestar ontem. Segundo a assessoria, qualquer mudança de controle acionário nas empresas de telecomunicações no Brasil terá de ser analisada pela agência. A assessoria informou ainda que a Anatel está analisando um pedido de anuência prévia para compra da Embratel pela Telmex. Segundo a assessoria, a Anatel não tem preferência por nenhuma das propostas apresentadas para compra da Embratel.

\section{Calais}

Em comunicado divulgado, a Calais, empresa formada pelas três operadoras diz que os documentos relativos à sociedade entre as teles e a Geodex já foram submetidos à apreciação da Anatel. E afirma que "não há qualquer tipo de 
acordo e/ou entendimento entre as operadoras e a Geodex que não esteja refletido nos contratos". Segundo o comunicado "o interesse das operadoras de telefonia fixa na Embratel limita-se ao negócio de dados e voz corporativa". A empresa afirma que em função disso haverá aumento da competição em diversos segmentos de atuação da Embratel.

O Dilema dos Prisioneiros trazido para a análise de um oligopólio simulado ilustra com nitidez a maneira como os resultados se redistribuem em função das políticas adotadas, ora cooperativa, ora competitiva, por empresas que operam em uma estrutura oligopolizada, mantidas inalteradas as políticas governamentais. Enquanto no monopólio (cooperação tácita ou conluio) o sucesso da estratégia se concentra nas mãos dos vendedores, isto é, quando cooperam todas as empresas realizam lucros; no oligopólio o sucesso é alcançado em termos relativos, ou seja, alguns vendedores ganham e outros perdem. Ademais, os efeitos da competição ora negativos, ora positivos, alcançam outros importantes grupos de interesses.

A estratégia de cada empresa redistribui os resultados, beneficiando algumas e prejudicando outras, tal qual ocorre com as empresas reais (equilíbrio de Nash). Quando analisamos os resultados agregados do setor estudado, notamos que a competição destruiu valor dos investidores. A redução dos lucros fez cair o preço das ações e precipitou uma artificial distribuição de dividendos, não sustentável em face dos resultados. Na tentativa de atrair os acionistas, os gestores adotam práticas inadequadas que retardam a saída do acionista, mas agravam a situação financeira das empresas.

A concorrência transformou os lucros médios da cooperação em prejuízos, para a maior parte das empresas, reduzindo dramaticamente a atratividade do setor. Tal equilíbrio tem grande relevância no estudo dos mercados imperfeitos. Não se pode ingenuamente concluir que a competição por si só seja prejudicial. Entretanto podese reconhecer que entre cooperar tacitamente e competir agressivamente existem ‘infinitas' maneiras de se estabelecer uma estratégia equilibrada e sustentável com a qual se possa, legalmente, cooperar na competição.

No oligopólio, os competidores em pequeno número podem fazer uso da comunicação para lidar com a limitação de informações sobre o mercado, sem necessariamente transgredir as normas legais vigentes. Podem promover interações não mercadológicas por meio de um sindicato, dividindo custos fixos ou despesas comuns, compartilhando centros de distribuição e recursos de logística, reduzindo elos no canal de distribuição, usando centrais de compras para obter fatores de produção com melhores preços, condições de pagamento e entrega; contratando pesquisas de mercado sindicalizadas que custam muito menos do que as pesquisas customizadas e ajudam a identificar os principais atributos valorizados pelos consumidores. 
A cooperação deveria ser possível sem imputar ônus aos consumidores. Se, por um lado, a competição oligopolística parece proteger o direito do consumidor ao se estabelecer no mercado um preço médio inferior ao que seria praticado sem competição, por outro as empresas que concorrem pela participação de mercado estão muito mais sujeitas às incertezas do mercado, dependentes da qualidade de sua estratégia. $\mathrm{O}$ fracasso de um dos competidores pode ameaçar $\mathrm{o}$ suprimento regular da demanda do setor, como no caso da Parmalat.

O que tem feito grupos investidores decidirem pela atuação em um determinado setor tem sido a facilidade de entrada e o poder de que dispõem e que materializa a geração de lucros. Em um extremo, encontram-se os monopólios que, devido a excessivo poder, não se ocupam em captar as necessidades dos consumidores. Por isso passaram a ser combatidos nos países em que prevalece economia de mercado. Apesar das mudanças observadas nos últimos 20 anos, alguns monopólios resistiram à abertura da economia brasileira, dentre eles os monopólios naturais de serviços públicos. Depois da quebra do monopólio da Petrobrás no setor de petróleo, o que trouxe novas empresas e novas tecnologias para a área de prospecção de petróleo, as autoridades ainda hesitam em quebrar o monopólio do IRB - Instituto de Resseguros do Brasil que, segundo especialistas, vende produtos tecnologicamente desatualizados por preços acima do valor que entrega. Neste caso, o papel do governo na regulamentação torna-se fundamental, podendo sujeitar-se aos humores e interesses políticos dos governantes.

Nos oligopólios, o poder diluído pode ser recuperado em decorrência de conluios. No caso de representarem ameaças ao equilíbrio econômico, intervenções governamentais podem fazer-se necessárias para defender o interesse da população, evitando fusões ou aquisições concentradoras de poder, acordos setoriais que beneficiem unilateralmente gestores e investidores, e prejudiquem os consumidores. Algumas vezes os concorrentes pleiteiam apoio do governo na forma de políticas tributárias mais flexíveis para enfrentar crises econômicas. A redução do IPI no setor automobilístico brasileiro foi adotada em 2003 para estimular as vendas; o setor de transportes aéreos, ameaçado pelo elevado nível do endividamento, vem há anos solicitando benefícios do governo. A compra da Chocolates Garoto pela Nestlé foi cancelada por exigência do CADE, por acreditar ser excessiva a concentração de poder nas mãos de uma única empresa. Neste momento discute-se a elevação de tarifas telefônicas, caso ocorra a aquisição da Telefônica pela Embratel.

Mais do que depender de apoio governamental, as empresas muito podem fazer para que prevaleçam suas estratégias, mesmo em setores com atratividade tradicionalmente baixa. A estratégia de diferenciação da TAM e a estratégia de custo total mínimo da GOL, ambas transportadoras aéreas, são distintos exemplos 
de estratégias bem sucedidas num setor com atratividade tradicionalmente baixa. Quando se pensa em crescimento sustentado, portanto, deve-se levar em conta os principais agentes econômicos responsáveis por isso.

\section{Conclusões e Contribuições}

Neste estudo explorou-se a idéia de que estratégias opostas adotadas por empresas oligopolistas distribuem, de forma assimétrica, riqueza e bem-estar entre os grupos envolvidos. A cooperação poderia sugerir que o oligopólio operou de maneira ilegal e irregular ao estabelecer, em benefício próprio, um acordo de preços. Isto, no experimento aqui relatado, não se observou, porquanto os preços foram apenas corrigidos conforme a inflação. O conluio 'responsável' aqui descrito produziu lucros para o oligopólio, garantindo atratividade positiva ao setor e mantendo a rentabilidade que os investidores esperam obter como retorno de seu investimento, sob pena de transferirem o capital investido para setores mais atrativos. A cooperação assegurou também o abastecimento pleno do mercado e a sustentabilidade das operações junto aos fornecedores e clientes, apesar de ter contribuído menos para gerar riqueza ao país e distribuir renda. Esta prática foi freqüente na década de 70 e 80 no Brasil.

A cooperação revela-se uma oportunidade de se promover encontros entre representantes dos grupos envolvidos, para que se definam políticas capazes de distribuir benefícios entre os agentes econômicos. Governo e sociedade têm, ambos, papéis importantes na definição de políticas públicas que harmonizem tal distribuição dos benefícios. Conflitos de interesses deverão ser administrados, para que empregos sejam gerados e mantidos, produtos tenham melhoria constante de qualidade e alcancem maior número de pessoas, fornecedores prosperem e acionistas obtenham retornos sobre seus investimentos. Tal tema torna-se particularmente importante, quando se preparam, no Brasil, as discussões sobre os mercados regionais. As decisões daí advindas não refletem apenas opiniões de diferentes camadas da sociedade, mas intenções que revelam culturas de diferentes nações. AALCA é um perfeito exemplo de que se deve estar preparado para defender posições unilaterais, sem perder-se de vista a perpetuação das relações com os parceiros da América.

Gestores de empresas e estudantes devem preparar-se para a realidade inexorável representada pelos mercados regionais. Evitá-los parecerá demasiado simplista diante do jogo de forças e interesses presentes nas dezenas de nações envolvidas. Impedir o avanço do processo parecerá menos sábio do que se preparar para influenciar sua evolução. Entendido o problema estratégico e as consequiências 
da cooperação e da competição, cabe aos acadêmicos inserirem em seus cursos oportunidades em que os estudantes possam cooperar na competição e desenvolver habilidades não valorizadas no passado, essenciais no presente e inevitáveis para a sustentabilidade das relações no futuro.

\section{Figura 1: Efeitos da Competição: Ganhos e Perdas}

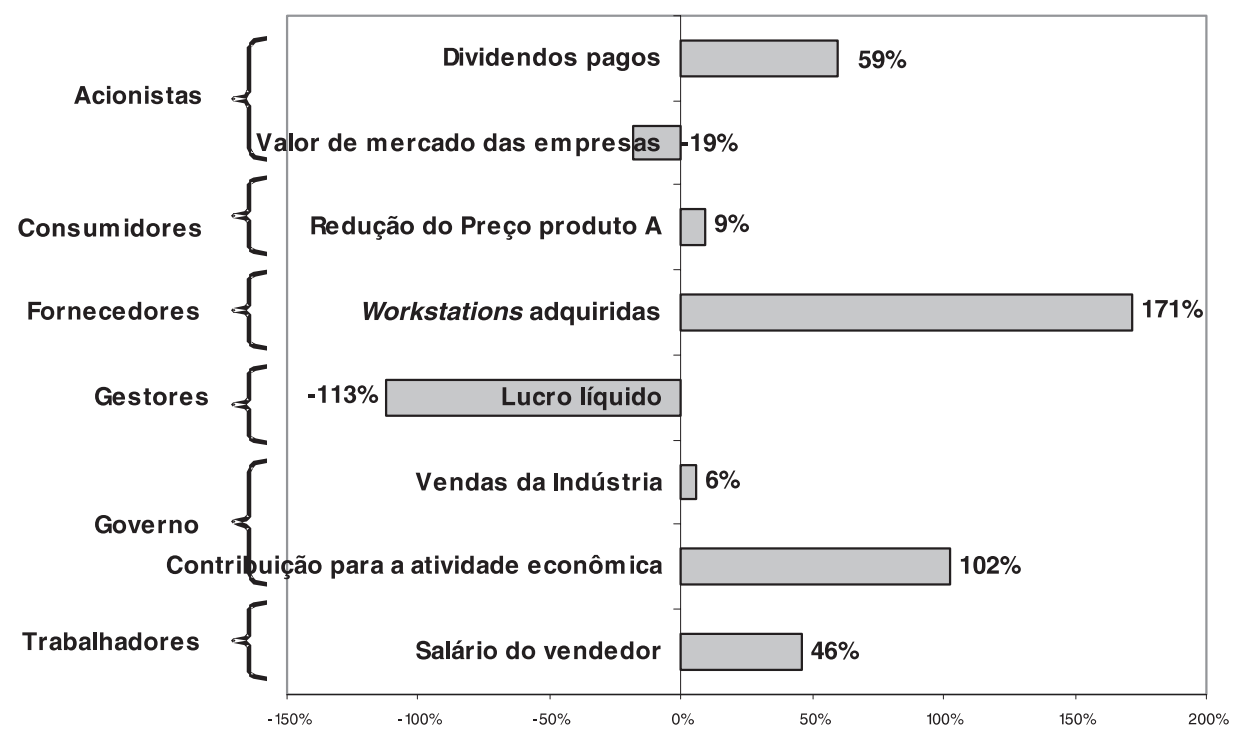

Os resultados no ambiente competitivo mostraram-se bastante distintos do ambiente cooperativo (Figura 1). Enquanto a cooperação beneficiou o governo e os gestores, gerando impostos e lucros mais elevados, a competição promoveu a qualidade dos produtos, maiores esforços no canal de distribuição, a prática de preços médios reduzidos, o aumento da atividade econômica e a geração de novos empregos. Além de produtos tecnologicamente superiores, foram produzidos e vendidos mais produtos, o que fez com que mais consumidores tivessem acesso ao mercado. Este fato pode ser interpretado como contribuição social decorrente da competição. Seria desejável que tal contribuição fosse sustentável, sem ameaçar os interesses dos investidores nem reduzir ou anular perigosamente a atratividade do setor. $\mathrm{O}$ desenho da Figura 1 pode sugerir que a competição gerou benefícios para a maior parte dos stakeholders. Tal idéia é equivocada, visto que, a persistir tal nível de competição, a sustentabilidade da indústria estaria ameaçada, frustrando geração de riqueza, impostos e empregos e descontinuando operações na cadeia econômica.

Pode-se concluir como segue. 
a) No experimento cooperativo (coalizão tácita), os lucros das empresas foram superiores. A cooperação 'aumentou o bolo' dos gestores, beneficiando os competidores sem transgredir de forma explícita as regras de mercado e imputou a uma parcela da sociedade (consumidores) um custo adicional de $9 \%$, oferecendo a garantia de uma estrutura de mercado estável e sustentável (o MMG - versão 1992, não propõe um simples jogo de 'soma zero').

b) No experimento competitivo a atratividade da indústria desabou, o que tenderia a afastar os investidores e provocar ruptura na estrutura do mercado. Rejeitouse a hipótese H01, visto que os lucros da cooperação se transformaram em prejuízos na competição. Consumidores e fornecedores obtiveram ganhos expressivos que não se mostram sustentáveis no longo prazo. Repetiu-se aqui o fraco desempenho médio da indústria de computadores reportado entre 78 e 96 por Ghemawat (2000, p. 32). A indústria global de computadores continua problemática como mostra a recente compra da Compac pela HP, para fortalecimento de ambas.

c) O limite entre legalidade e ilegalidade é tênue. A regulamentação de oligopólios pode ser alternativa eficaz para defender a indústria (gestores e investidores) e, ao mesmo tempo, proteger os grupos de interesse (consumidores, fornecedores, trabalhadores e governo).

Ganhos e perdas obtidos por meio da cooperação podem ser considerados ilícitos, estando sujeitos às penalidades da lei e a eventuais intervenções do CADE Conselho Administrativo de Defesa Econômica. Somente em 2003 o CADE analisou 581 casos de quebra das regras concorrenciais, realizou 200 investigações contra possíveis cartéis, promoveu 14 batidas policiais coordenadas pela SDE, Secretaria do Direito Econômico. Como resultado dessas ações, 370 empresas brasileiras estavam, no final de 2004, sob supervisão da CVM, Comissão de Valores Mobiliários. Somente em 2004 as multas somaram 65 milhões de reais e 24,2 milhões em 2003. O tempo médio gasto pela CVM para concluir uma investigação é de 3,5 anos. Em 2004 o CADE examinou 1000 processos de cerca de 2000 empresas em questões relativas à ética na concorrência, em fusões e aquisições e no relacionamento de empresas com o mercado de ações (Mano, 2004, p. 24-25).

Este estudo não esgota o tema. Pelo contrário, contribui modestamente para promover uma discussão fundamental que envolve diversas correntes da sociedade. 


\section{Limitações e Proposições}

O valioso recurso dos modelos econômicos que simplificam a realidade complexa é, ao mesmo tempo, sua limitação. O mesmo se nota com os Jogos de Empresas, programas computadorizados para representar aspectos do ambiente das organizações, onde está presente um número muito menor de variáveis da realidade complexa. Cabe também, em novo estudo, analisar os efeitos em separado da competição sobre cada um dos fabricantes. Ademais, não se pode generalizar os resultados deste estudo, pois se trata de amostra única, sendo desejável a repetição do experimento com este e outros simuladores para ampliar os dados e os 'insights'.

Para aprimorar os modelos de simulação na indústria de computadores, Brandenburger e Nalebuff (Ghemawat, 2000) recomendam a inclusão de aspectos relacionados aos agentes 'complementadores', fundamentais em uma 'rede de valor'. Outros modelos de simulações empresariais devem ser testados em condições similares, replicando-se este estudo e comparando-se os resultados aqui apresentados.

\section{Artigo recebido em 06.04.2005. Aprovado em 01.07.2005.}

\section{ReferênCIAS Bibliográficas}

Chandler, A. D., Jr. (1977).

The visible hand: the managerial revolution in American business. Cambridge, MA: Harvard University Press.

Douglas, E. J. (1992).

Managerial economics: analysis and strategy. NJ: Prentice Hall.

Faria, A. J. (2000).

The changing nature of simulation research: a brief ABSEL history. Developments in business simulation and experiential learning (Vol. 27, pp. 84-90). Recuperado em 01 agosto, 2002, de http://www.absel.org
Ghemawat, P. (2000).

A estratégia e o cenário dos negócios: texto e casos. Porto Alegre: Bookman.

Gremaud, A. P., \&

Braga, M. B. (1998).

Teoria dos jogos: uma introdução. In A. F. Montoro Filho, A. P. Gremaud, A. E. T. Lanzana, C. A. Luque, C. M. Pinho, D. C. O. Alves et al. (Orgs). D. B. Pinho \& M. A. S. de Vasconcelos (Coords.). Manual de economia (3a ed., pp. 243-260). São Paulo: Saraiva. 
Keys, J. B.,

Edge, A. G., \&

Wells, R.A. (1992).

The multinational management game - A game of global strategy (3rd ed.). Homewood, Illinois: Irwin.

Kreps, D. M. (1990).

Game Theory and economic modeling. Oxford: Clarendon Press.

\section{Kreps, D. M.,}

Milgrom, P.,

Roberts, J., \&

Wilson, R. (1982).

Rational cooperation in the finitely repeated prisoners' dilemma. Journal of Economic Theory, 27(2), 245-52.

Mano, C. (2004, novembro 10).

Eles controlam o mercado. Exame, ano 38 (22), 24-5.

Nowak, M. A.,

Sigmund, K., \&

Leibowitz, M. (2000).

Cooperation versus competition. Financial Analysts Journal, 56(4), 13-22.

Owen, G. (1995).

Game theory. San Diego: Academic Press.

Pindyck, R. S., \&

Rubinfeld, D. L. (1994).

Microeconomia. São Paulo: Makron Books.

Porter, M. (1985).

Estratégia competitiva: técnicas para análise de indústrias e da concorrência. Rio de Janeiro: Campus.
Sauaia, A. C. A. (1997).

Jogos de empresas: aprendizagem com satisfação. Revista de Administração da USP, 32(3), 13-27.

Sauaia, A. C. A., \&

Kallás, D. (2003).

Cooperate for profits or compete for market? Study of oligopolistic pricing with a business game. Developments in Business Simulation and Experiential Learning (Vol. 30, pp. 232-42). Recuperado em 01 agosto, 2003, de http://www.absel.org

Sauaia, A. C. A., \&

Kallás, D. (2004).

Cooperar pelos lucros ou competir pelo Mercado? O conflito do oligopólio tratado em um jogo de empresas. Anais do Encontro Nacional dos Programas de PósGraduação em Administração, Curitiba, PR, Brasil, 28.

Silbiger, S. (1996).

MBA em dez lições. Rio de Janeiro: Campus.

Spínola, M. R. P., \&

Troster, R. L. (1998).

Estruturas de mercado. In A. F. Montoro Filho, A. P. Gremaud, A. E. T. Lanzana, C. A. Luque, C. M. Pinho, D. C. O. Alves et al. (Orgs). D. B. Pinho \& M. A. S. de Vasconcelos (Coords). Manual de economia (3a ed., pp. 181194). São Paulo: Saraiva.

Zimmermann, P. (2004, abril 26).

SDE vai investigar acordo das telefônicas. Folha Online. Recuperado em 27 abril, 2004, de http:/ /www1.folha.uol.com.br/folha/ dinheiro/ult91u83576.shtml 